\title{
Influence of Study Habits on Undergraduate Nursing Students' Academic Performance in University of Calabar, Nigeria
}

\author{
1 Ella, R. E. FWACN, RN/RM, RNT, Ph.D Senior Lecturer \\ ${ }^{2}$ Akpabio, I.I. FWACN, RN/RM, RPHN,Ph.D Associate Professor \\ ${ }^{3}$ Samson-Akpan, P.E. FWACN, RN/RM, RNT,Ph.D. Associate Professor \\ Department of Nursing Sciences, University of Calabar, Calabar, Nigeria
}

\begin{abstract}
:
Background: Poor performance of undergraduate nursing students in the university and professional examinations in recent times is a source of concern to both educators and other stakeholders. This study was conducted to determine the influence of study habits on undergraduate nursing students' academic performance in the University of Calabar, Nigeria.

Methods: A cross sectional descriptive study was conducted in 2012 with 160 students who were in years 3 to 5 of their studies. These were selected through simple random sampling technique. Data was collected using selfconstructed study habits inventory questionnaire with content validity index of 0.79 and a test-retest reliability coefficient of 0.81 . Copies of the questionnaire were completed by the students in a classroom setting after which achievement tests were administered simultaneously based on the objectives of the course. Data was analysed using Independent t-test.

Results: The result obtained from the analysis of the study revealed that majority of the participants were fourth year students $(72 ; 45 \%)$, followed by third year $(64 ; 40 \%)$ and fifth year students $(24 ; 15 \%)$. There were no significant differences in academic performances of the students who practiced group and individual studies, those who read at the library hostel or away from the library and those who read at daytime compared to night time. Conversely, there were significant differences in academic performance between students who had $75 \%$ and above class attendance and others with less than $75 \%$ attendance.

Conclusion: The result of this study affirms the fact that class attendance influences academic performance of students. Therefore, there is need to enforce mandatory $75 \%$ class attendance for undergraduate nursing students to enhance their academic performance. Despite the insignificant results between hostel and library reading, the library should be made more conducive for reading with necessary facilities to encourage usage.
\end{abstract}

Keywords: Study habits, Academic performance, Undergraduate nursing students, Influence, University of Calabar

\section{INTRODUCTION}

Reports exist, of students' poor academic performances in the Nigerian educational system (Oluwatimilehin and Owoleye, 2012). These poor performances cut across different fields of education including nursing education. The poor academic performances can lead to inadequate knowledge needed to enhance professional skills required for nursing procedures. A poorly trained nurse becomes a threat to the lives of the patients, and further compounds the already poor state of the healthcare in Nigeria (Dimkpa, Inegbu and Buloubomere, 2013). Academic performance can be viewed as ability to study and remember facts and to be able to express such knowledge gained either verbally or in writing. It is a key criterion to judge ones total potentialities and capabilities which are frequently measured by examination results and used to pass judgement on quality of education by academic institutions. Students' academic performance also plays an important role in producing best quality graduates who will become great leaders and manpower for the country thus responsible for the country's economic and social development (Alos, Caranto, and David, 2015). Academic performance to a great extent is a function of students study habits. Therefore to enhance education, it becomes necessary to improve study habits of students. Globally researches revealed that a relationship exists between study habits and academic performance (Bashir and Mattoo, 2012; Kurshid, Tanveer and nas Quasmi, 2012). Study habits are students' ways of studying whether systematic, efficient or inefficient (Ayodele and Adebiyi,2013), implying that efficient study habits

${ }^{1}$ Corresponding Author: retila07@yahoo.com 
produces positive academic performance while inefficient study habits lead to academic failure. Awareness to this by stakeholders through research findings remains the bedrock of this strategy.

Dimkpa, Inegbu and Buloubomere, 2013), researched on causes of poor academic performance of student nurses in Bayelsa state School of Nursing in Nigeria, and recommended students' formation of study groups to improve on academic performance. In group studies students who possess positive study habits help others to understand some difficult concepts, complete assignments, and to internalize information. However, Thomas (2011) argued that in a group it is easy for unserious students to negatively influence others.

Studies on influence of class attendance on academic performance of students have revealed a positive correlation (Bratti and Staffolani, 2002; Aden, Yahye, and Dahir, 2013). The investigation of Aden et al on the relationship between students' attendance and academic performance at SIMAD University yielded a moderate positive relationship. They recommended that Universities should maintain strict guidelines for student's class attendance. However, Bratti and Staffolani (2002) argued that students' performances to a large extent depended on students' intelligence quotient (IQ) and not on the class attendance; therefore mandatory attendance policy would not significantly enhance performance.

Jato, Ogunniyi, and Olubiyo (2014), Cox and Jantti (2012), studies revealed a positive relationship between use of library and academic performance. Shield and Dockrell (2008) compared the academic performances of students who studied in noisy environments with students who studied in quiet environments and found that students in noisy environments scored lower. They reported that students who studied in noisy environments expressed symptoms of stress which affected their academic outputs.

Shin, Kim, Lee, Ahn, and Loo (2003) researched on sleep habits, and school performance of students. Result revealed positive relationship between night reading, excessive day-time sleepiness with a decline in school performance. On the contrary Kazim and Abrar (2011), Ali, Majeed, Saba, Bodenarain and Bukhari (2013), studies on sleep patterns and the relationship with academic performance revealed no firm relationship; they concluded that different sleeping patterns do not affect the academic performance. Some students prefer to read at night while others prefer to read in the day depending on their schedule. No matter the time, what mattered was for the student to understand and assimilate what she studied.

In Nigeria, the Nursing and Midwifery Council of Nigeria (N\&MCN) conducts two examinations for Nurses and Midwives, yearly (these are often times referred to as professional licensure examinations ).The examination for general nurses is conducted in May and November; and March and September for midwives. Success in these examinations registers the nurse or midwife with the N\&MCN and licences him or her for practice. The generic nursing students write the Council General Nurses Examinations in their $4^{\text {th }}$ year and the University degree examinations in their 5th year. Poor performances in these examinations have been consistent in recent times. From May 2005 to November 2014, sixteen (16) of the council examinations were written by different sets of nursing students. Five out of the sixteen results ranged from $67 \%$ to $69 \%$, while eleven ranged from $8 \%$ to $42 \%$. If this consistent high rate of failure continues unchecked, the Nursing department may lose its reputation with resultant loss of confidence in the graduates from this Department in particular. In general, poor performance may translate to poor standards of nursing practice and patient outcomes which does not make for quality care.

A few researches on nursing students' academic performances in this setting have focused on variables such as sex, anxiety, socio economic, age etc. This fact justifies the need to examine some aspects of study habits in relation to nursing students' academic performances. The study will add to the current literature on the subject and will serve as baseline for future researchers. It is against this background that the researchers sought to determine if study habits have any influence on undergraduate nursing students' academic performance in the Department of Nursing Science University of Calabar. Specifically the objectives were:

$>$ To determine the influence of group or individual study on undergraduate nursing students' academic performance.

$>$ To determine the influence of class attendance on undergraduate nursing students' academic performance.

$>$ To determine the influence of studying in the library or outside the library on undergraduate nursing students' academic performances.

$>$ To determine the influence of study day or night on undergraduate nursing students' academic performances.

\section{MATERIALS AND MethodS}

A cross sectional descriptive survey research method was adopted. The setting was Cross River State which is one of the thirty six (36) states of the Federal Republic of Nigeria, with eighteen (18) Local Government areas (LGAs). The study site is Department of Nursing Science, University of Calabar. The Department offers admissions annually and trains 
generic undergraduate nursing students through a five year degree program, and four years degree program for direct entry nursing students.

The target population was generic undergraduate nursing students in the department who were in years three (3) to five (5) totalling three hundred and fifty (350). This figure constituted the accessible population. Simple random sampling technique of balloting was used to select 160 students from the 350 students. Generic students were considered for this study because they only write the council examination. However, generic students from years one (1) to two (2) were excluded; also direct entry students were excluded because they are already registered nurses with the Council. Data was collected through a questionnaire and class achievement test, which were designed and administered by the researchers. Positive comments by experts were suggestive of the face validity of the instrument. A measure of stability over time was assessed using a test re-test procedure which yielded a correlation coefficient ( $r$ ) of 0.81 . The achievement test generated nursing students' scores, while the questionnaire elicited information on socio-demographic data and undergraduate nursing students' study habits.

\subsection{Ethical Considerations}

A written permission to undertake the study was obtained from the ethical and review committee of the University following the authors' submission of the research proposal. Written permission was also obtained from the Acting Head of Department of Nursing. Informed consent was obtained from the students. The students were assured that none of them will be penalised for refusing to participate in the study. All those recruited for the study gave consent to participate; anonymity was ensured.

\subsection{Data Analysis}

Generated data was analysed using descriptive statistics of frequencies and percentages, non-parametric tests (the independent t-test).

\section{RESULTS}

This section presents the results obtained from the analysis of data and testing of hypothesis formulated for the study. The results are presented in tables followed by their interpretations and discussion of findings.

Table1. Socio-Demographic Data

\begin{tabular}{|l|l|l|}
\hline Variables & Frequency & Percent \\
\hline Sex & 12 & \\
Male & 148 & 7.5 \\
Female & 160 & 92.5 \\
\hline Total & 3 & 100.0 \\
\hline Age & 157 & \\
Below 20 years. & 160 & 1.9 \\
21-30 years. & & 98.1 \\
\hline Total & 64 & 100.0 \\
\hline Year of Study & 72 & \\
3rd year. & 24 & 40.0 \\
4th year. & 160 & 45.5 \\
5th year. & & 15.0 \\
\hline Total & 134 & 100.0 \\
\hline Marital Status & 25 & \\
Single & 1 & 83.8 \\
Married & 160 & 15.6 \\
Divorce & & .6 \\
\hline Total & 160 & 100.0 \\
\hline Religion & - & \\
Christian & - & 100.0 \\
Muslim & 160 & - \\
Others & & - \\
\hline Total & & 100.0 \\
\hline
\end{tabular}

Table 1shows the distribution of the demographic characteristics of 160 respondents who participated in the study. Majority of the respondents were females $(148 ; 92.5 \%)$ while the remaining $(12 ; 7.5 \%)$ were males. One hundred and fifty seven respondents $(157 ; 98.1 \%)$ were between the ages of $21-30$ years; only $(3 ; 1.9 \%)$ were below 20 years. Furthermore majority $(72 ; 45.0 \%)$ of the respondents were $4^{\text {th }}$ year students; $(64 ; 40.0 \%)$ were $3^{\text {rd }}$ year students; while $(24 ; 15.0 \%)$ were $5^{\text {th }}$ year students. In addition, 20 respondents were employed, 32 were into business while the remaining 
were full time students. Majority of the respondents $(138 ; 83.8 \%)$ were single; $(25 ; 15.6 \%)$ were Married; while the remaining $(1 ; 1.06 \%)$ were divorced. All the respondents were Christians.

Table2. The table presents the results obtained from the analysis and testing of hypotheses 1-4

Table2. Independent $t$-test analysis of the differences in academic performances of undergraduate nursing students based on their study habits.

\begin{tabular}{|l|l|l|l|l|}
\hline Groups & $\mathrm{N}$ & Mean X & SD & $\mathrm{t}$ \\
\hline Group study & 110 & 6.65 & 3.221 & \multirow{2}{*}{0.569} \\
Individual study & 50 & 6.34 & 2.980 & \multirow{2}{*}{$5.437^{*}$} \\
\hline 75\% class attendance and above & 127 & 17.17 & 2.725 & \\
Less than 75\% class attendance & 33 & 4.33 & 2.420 & -0.362 \\
\hline Studying in the library & 52 & 6.46 & 2.509 & \\
Studying away from the library & 108 & 6.65 & 2.074 & \multirow{2}{*}{0.139} \\
\hline Day time studying & 46 & 6.83 & 3.421 & \\
Night time studying & 114 & 6.75 & 2.741 & \\
\hline
\end{tabular}

*Significant at $.05 ; d f=158 ;$ Critical $t=1.976$

Explaining the results in table 2:

There is no significant difference between undergraduate nursing students who studied in group and those who studied individually $($ Cal. $\mathrm{t}=0.569<$ Crit.t $=1.976$; df $158 ; \mathrm{P}<0.05)$.

There is significant difference between undergraduate nursing students with $75 \%$ and above class attendance and those with less than $75 \%$ class attendance (Cal. $\mathrm{t}=5.437>$ Crit.t $=1.976$; df $158 ; \mathrm{P}<0.05)$.

There is no significant difference between undergraduate nursing students who studied in the library and those who studied away from the library (Cal. $\mathrm{t}=0.362<$ Crit.t $=1.976$; df $158 ; \mathrm{p}<.05$ )

There is no significant difference between undergraduate nursing students who studied in the day and those who studied in the night time (Cal. $\mathrm{t}=0.139<$ Crit.t $=1.976$; df 158; $\mathrm{P}<0.05)$.

The results of group or individual study, class attendance, studying in library or away from the library and day time or night study are as indicated in table 2.

The results revealed a non significant difference in the academic performances of nursing students who studied in group and those who studied individually. Also no significant difference in the mean scores of students who studied in group and those who studied individually. Hence both the undergraduate nursing students that studied in group reading and their colleagues that studied individually do not differ in terms of academic performances.

For class attendance :The result showed that students who attended classes regularly had a higher mean score of 17.17 compared with those who did not attend classes regularly with a mean score of 4.33 . Hence there was a significant difference in the academic performances of undergraduate nursing students who attended classes regularly and those who did not.

For use of library: The result revealed that there was no significant influence of studying in the library on the academic performances of undergraduate nursing students. Undergraduate nursing students who studied in the library and those who did not had similar mean scores of 6.46 and 6.65 respectively, indicating an insignificant difference. Hence null hypothesis was accepted.

For day or night time studying: The result revealed that nursing students who read at night and those who read in the day time had similar mean scores of 6.83 and 6.75 respectively, indicating an insignificant difference. Therefore the null hypothesis was accepted implying no significant difference in the academic performances of nursing students who studied at night and those who studied in the day time.

\section{DISCUSSION}


The result revealed that group or individual study did not significantly influence the undergraduate nursing students' academic performances since their academic performance did not vary. The finding was contrary to that of Dimkpa et al (2013) who also recommended the formation of study groups to enhance academic performance. The finding is supported by the assertion of Thomas (2011) that group study has numerous challenges because individual students who constitute the study group have different businesses they wish to accomplish at the times which the group will prefer to study; that it is also easy for unserious students to negatively influence the entire group. What matters is how the students go about their study. Whether a student prefers group or individual study, choosing the right place, the right time and the right partners will certainly help to incite interest in the student's mind, direct the student in the right path towards success, as well as improve academic performances.

A significant difference was revealed between the academic performances of undergraduate nursing students who attended classes regularly and those who did not. This finding may be related to the area of study. In the University of Calabar, it is mandatory that students have seventy five (75\%) class attendance to be eligible to write any examination. This policy is supported by the recommendations of Aden et al (2013) that universities should develop and maintain strict guidelines for students' attendance and monitor factors that could hinder a student from attending classes on a regular basis. This finding therefore supports the assertion that attendance in school is important because students are more likely to succeed in academics when they attend classes consistently. Although some researchers like Bratti \& Staffolani, (2002), have maintained that students' performances in most cases depended to a large extent on students' intelligence quotient (IQ) and not on class attendance; regular class attendance allows students the opportunity to get first hand information and understand the subject matter being taught by the teachers. But when students fail to attend classes regularly, they would lack understanding, especially in subjects that are difficult to understand.

There was no statistically significant difference in the academic performances of undergraduate nursing students who studied in the library and those who studied away from the library; this was contrary to the findings of Ogunniyi, and Olubiyo (2014), Cox and Jantti (2012), whose studies revealed better results among students who use the library for their studies. This result was however surprising because the University library is adequately equipped and is a more quiet environment for studying. However, the non preference for the library use could be associated with the lack of modern Information, Communication and Technology (ICT) resources particularly poor internet services, with continuous epileptic nature of power supply. These can cause unconducive environment for study may result to the non preference for the library. The findings notwithstanding the library is still the best place for quiet study because it offers privacy, reading materials, reference materials, and a quiet atmosphere and where possible continuous and comfortable lighting, also computers, printers, and email stations.

Furthermore the findings of this study revealed that there is no significant difference in the academic performances of undergraduate nursing students who studied at night and those who studied in the day. Though this finding is contrary to the result of Shin et al (2003) that night reading results in poor sleep quality, stress, risk of psychological morbidity, burnout and impairs academic performance. This findings may be attributed to the area of study and the nature of the nursing program, where because of the mandatory policy of $75 \%$ attendance the students spent the whole of the day time attending classes leaving them with little or no time to rest and review the days teachings, thus students might have conditioned themselves to making use of any time within the 24 hours whether night or day to study, depending on when they found time and would assimilate better, implying that no matter the time a student preferred to study, what mattered was for the student to understand or assimilate what he or she studied.

The significant result of class attendance to students' academic performance affirms the assertion of Bashir and Mattoo, (2012) and Kurshid, Tanveer and nas Quasmi, (2012) that a relationship exists between study habits and academic performance. There is therefore need for stakeholders to work towards the improvement of students' academic performance as this plays an important role in producing best quality graduates who will become great leaders and manpower for the country thus responsible for the country's economic and social development (Alos, Caranto, and David, 2015)

There are other study habit variables that could have acted to influence undergraduate nurses' academic performances as indicated in previous studies. However this study focused on the students study habits in respect of group or individual study, class attendance, period of study and use of library as they influence undergraduate nurse academic performances. Future studies among this group of students may also need to focus on other variables.

\section{CONCLUSIONS AND RECOMMENDATIONS}


The findings of this study affirms the fact that class attendance influence academic performance of students. This is a demonstration that good study habits could be very instrumental to students' academic success. Group or individual study, study time, library or outside library study did not reveal any significant difference. Another study using other study habit variables is recommended. Notwithstanding the insignificant influence demonstrated between group or individual study, night or day time study, and studying in library or away from the library on undergraduate nursing students' academic performance it is recommended that students should choose: study partners that would not influence them negatively, study times that would not negatively affect their health and assimilation, and study environments that would enhance assimilation of their reading materials. Above all, they should attend classes regularly since this was seen to have positive influence on academic performances. There is need for the Universities to enforce mandatory $75 \%$ class attendance for all the students; also despite the insignificant results between outside and library reading, the library should be made more conducive for reading with necessary facilities to encourage usage. The significance of class attendance of nursing students to their academic performance indicates the need for nurse educators and other stakeholders to counsel students' in this respect because nursing programs require more of physical presence to improve academic performances, improve on the quality of trained nurses who will in turn offer quality nursing care.

There are other variables that could have acted to influence academic performance of undergraduate nursing students such as indicated in previous studies. However, this study focused only on the students' study habits such as group or individual study, class attendance, use of library and period of study. Future studies among this group of students may also need to focus on those other variables.

\section{REFERENCES}

[1] Aden, A.A; Yahye, Z. A and Dahir, A.M (2013) The Effect of Student's Attendance on Academic Performance: A Case Study at Simad University Mogadishu Educational and Management Sciences SAVAP International (4) 6

[2] Ali, A; Majeed, M. B; Saba, K; Bodenarain, A; Bukhari, M. H. (2013). The Effects of different sleeping patterns on academic performance in medical School students. Natural Science 5(11) 1193-1198

[3] Alos, .S. B, Caranto, L. C, \& David, J. J. T (2015) Factors Affecting the Academic Performance of the Student Nurses of Benguet State University International Journal of Nursing Science 5(2): 60-65

[4] Ayodele, C.S and Adebiyi, D.R (2013). Study Habits as Influence of Academic Performance of University Undergraduates in Nigeria. Research Journal in Organizational Psychology \& Educational Studies 2(3) $72-75$

[5] Bashir, I. \& Mattoo, N.H. (2012). A study on study habits and academic Performance of adolescents (14-19) years. International Journal of Social Science Tomorrow, 1 (5).

[6] Bratti, M., \& Staffolani, S. (2002). Student Time Allocation and Educational Production functions, Working Paper 170, Economics Department, University of Ancona.

[7] Cox, B and Jantti, M (2012). ) Discovering the Impact of Library Use and Student Performance. EDUCAUSE review.

[8] Dimkpa, D I; Inegbu and Buloubomere (2013) Student Nurses Perception of Poor Academic Performance in Bayelsa State, Nigeria. Global Journal of Human Social Science Linguistics \& Education. 13(14)

[9] Department of Nursing Sciences, University of Calabar, Nursing and Midwifery Council of Nigeria Examination Results Hand book, $2003-2015$

[10] Jato, M; Ogunniyi, S.O and Olubiyo, P.O (2014). Study Habits, Use of School Libraries and Students' Academic Performance in Selected Secondary schools. In Ondo West Local Government Area of Ondo State. International Journal of Library and Information Science 6(4) 54-67

[11] Kazim, M, \& Abrar, A. (2011) Sleep patterns and academic performance in students of a medical college in Pakistan. KUST Med Journal; 3(2): 57-60

[12] Khurshid, F., Tanveer, A., \& Qasmi, F. (2012). Relationship between Study Habits and Academic Achievement among Hostel Hiving and Day Scholars' University Students. British Journal of Humanities and Social Sciences, 3 (2), 34-42.

[13] Oluwatimilehin, J. T. B and Owoleye J W (2012) Study habits and academic Achievements in core subjects among junior secondary school students in Ondo state, Nigeria. Bulgarian Journal of Science and Education Policy (BJSEP), 6(1) Tai Solar in University of Education, Nigeria.

[14] Shield, B I and Dockrell J (2008). The effects of classroom and environmental Noise on children's academic performance Performance: 9th International Congress on Noise as a Public Health Problem (ICBEN), Foxwoods, CT

[15] Shin, C; Kim, J; Lee, S; Ahn, Y; and Loo, S (2003). Sleep habits excessive Daytime sleepiness and school performance in high school students. Psychiatric and Clinical Neurosciences. 57(4) 451-453.

[16] Thomas, P L (2011).Why the achievement gap matters and will remain. Natural Education Policy Centre. Available from http://nepc Colorado.edu/ 